\title{
Análise das experimentações político-pedagógicas vivenciadas em um projeto de extensão
}

Analysis of the political-pedagogical experiments experienced in an extension Project

\begin{abstract}
Autores
Luiz Eduardo de Almeida. Mestre em Clínica Odontológica. Professor do Departamento de Odontologia do Campus de Governador Valadares da Universidade Federal de Juiz de Fora (UFJF-GV), Governador Valadares, Brasil.

Email: luiz.almeida@ufjf.edu.br

Valéria de Oliveira. Doutora em Saúde Coletiva. Professora do Departamento de Odontologia do Campus de Governador Valadares da Universidade Federal de Juiz de Fora (UFJF-GV), Governador Valadares, Brasil.

Email:valeria.oliveira@ufjf.edu.br

Marília Nalon Pereira. Doutora em Odontologia Restauradora. Professora do Departamento de Odontologia Restauradora da Faculdade de Odontologia da Universidade Federal de Juiz de Fora (UFJF-JF), Juiz de Fora, Brasil.

E mail: marilia.nalon@ufjf.edu.br.

Larisse Martins Aguiar. Acadêmica extensionista do curso de Odontologia do Campus de Governador Valadares da Universidade Federal de Juiz de Fora (UFJF-GV), Governador Valadares, Brasil.

Email: laa.risse@hotmail.com

Diego Machado de Oliveira. Acadêmico extensionista do curso de Odontologia do Campus de Governador Valadares da Universidade Federal de Juiz de Fora (UFJF-GV), Governador Valadares, Brasil.

E mail: diego-oliveira2608@hotmail.com

Autor responsável pela correspondência com a revista e com os leitores: Luiz Eduardo de Almeida.
\end{abstract}

Recebido em: 18/02/2019 Aprovado em: 04/09/2019

DOl: $10.12957 /$ interag.2019.40263

\section{Artigo}

\section{Resumo}

Objetivando compreender o fundamental papel da extensão universitária no provimento da articulação ensino-serviço-comunidade, o presente estudo teve como objeto analisar os dispositivos político-pedagógicos atrelados à dinamização do Projeto de Extensão Sala de Espera do Campus Avançado de Governador Valadares da Universidade Federal de Juiz de Fora. Assim, sob estratégia

\section{Abstract}

Aiming to understand the fundamental role of university extension in providing teaching-service-community articulation, the present study had as objective to analyze the political-pedagogical devices linked to the dynamization of the "Extension Project Waiting Room of the Advanced Campus of Governador Valadares of the Federal University of Juiz de Fora. Thus, under a narrative-descriptive strategy, the 
narrativo-descritiva, os integrantes do projeto de extensão buscaram não apenas criticar como refletir sobre as vivências experimentadas, didaticamente sistematizadas em dois períodos, Pré-intervenção (Contextualização dos acadêmicos extensionistas; Pactualização do enlace ensino-serviço-comunidade; Estruturação e ambientalização das equipes de trabalho) e Intervenção (Teorizando; Praticando; Criticando). Deste percurso algumas inferências se destacaram: 1) a importância da capacitação, da ambientalização e da estruturação das equipes multiprofissionais de trabalho; 2) o enlaçamento ensino-serviço-comunidade; 3) a efetividade do instrumento "TPC" na dinamização das atividades extensionistas; 4) o reconhecimento dos ambientes de espera como território dinâmico e fértil para a implantação de ações educativas; 5) a disseminação, em espaços científicos, dos aprendizados advindos da extensão. Por fim, das ponderações elencadas, este trabalho reforça ainda mais o fundamental papel da extensão universitária para uma formação acadêmica de qualidade e direcionada às solutividades das verdadeiras aflições que assolam a população brasileira.

Palavras- chave: Extensão universitária, Relações Interprofissionais, Relações Interinstitucionais, Relações Comunidade-Instituição

Área Temática: Educação

Linha Temática: Educação Profissional members of the extension project sought not only to criticize how to reflect on the experiences experienced, didatically systematized in two periods, Pre-intervention (Contextualization of the extensionist academics, Pactualization of teaching-service-community linkage, Structuring and environmentalization of work teams) and Intervention (Theorizing, Practicing, Criticizing). Some of these inferences were: 1) the importance of training, the environmentalization and structuring of multiprofessional work teams; 2) the teaching-service-community bonding; 3 ) the effectiveness of the "TPC" instrument in streamlining extension activities; 4) the recognition of waiting environments as a dynamic and fertile territory for the implementation of educational actions; 5) the dissemination, in scientific spaces, of learning from extension. Finally, from the above-mentioned considerations, this work reinforces even more the fundamental role of university extension for a quality academic education and directed to the solutions of the true afflictions that plague the Brazilian population.

Keywords: Univeristy Extension, Interprofessional Relations, Interinstitutional Relations, Community-Institutional Relations 


\section{Introdução}

Em junho de 2014, direcionado pelas demandas dos serviços públicos de saúde local, estruturou-se o Projeto de Extensão Sala de Espera do Campus Avançado de Governador Valadares da Universidade Federal de Juiz de Fora, PESE-UFJF/GV.

Neste movimento, o PESE-UFJF/GV não apenas pluralizou cenários práticos para uma formação mais direcionada às necessidades do Sistema Único de Saúde, SUS, bem como atuou no provimento da tão almejada articulação entre ensino (UFJF/GV, contexto teórico), serviço (Prefeitura Municipal de Governador Valadares, PMGV, contexto prático) e comunidade (usuários do SUS, contexto da integração entre teoria e prática).

Uma lógica de trabalho corroborante ao dito por Albuquerque1 e Madeira2, que reconhecem na extensão universitária um importante território acadêmico para a concepção do enlace ensino-serviço-comunidade. Neste engenho, os autores1,2 também destacam o fundamental papel desta articulação junto à reorientação da formação dos profissionais de saúde, afinal, são nos espaços extensionistas que se dão a socialização do resultado de um fato (pesquisa) e/ou de um aprendizado (ensino).

Alinhados ao contexto, Almeida, Pereira, Oliveira3 e Almeida, Pereira, Bara4 evidenciam que das vivências que promulgam a indissociabilidade entre ensino, pesquisa e extensão se dinamiza um círculo virtuoso, onde uma modalidade estimula a produção da outra, por conseguinte, promovendo a redução do persistente e fragilizante hiato entre o pensar e o fazer. Corroborando, sob ótica maior, alimentado pelos estudos de Tinti5, pode-se afirmar que a sustentabilidade do processo educacional se esbarra na dialética relação entre teoria e prática.

Entretanto, em contramão às preconizações supradescritas, conforme Almeida, Pereira e Oliveira3, p.744,

[...] apesar da esperada e crucial cooperação entre ensino, pesquisa e extensão, a competição prevaleceu. De um lado, a pesquisa e o ensino têm sido alvo de discussões que originaram elaborados sistemas de avaliação da produção científica e da qualidade dos cursos; já a extensão universitária, por outro lado, não recebeu a mesma ênfase, nem sofreu as transformações necessárias em ritmo e intensidade pertinentes para acompanhar a evolução do ensino superior. Neste percurso, a importante produção gerada pela extensão é geralmente pouco valorizada no plano acadêmico, onde prevalecem os critérios e o ranking dos periódicos indexados. Embora abundante, a produção de textos de, ou sobre, extensão acaba frequentemente no esquecimento das gavetas, nos CDs, em subdiretórios de computadores ou mesmo em locais pouco visitados na web.3

Fatalmente, realçado pelos seus protagonismos, vê-se a fragilização do hegemônico e tradicional modelo formativo acadêmico, em que, normalmente, o ensino e a pesquisa, juntos, seguem desconectados das questões sociais que os cercam, tornando-se majoritariamente idealistas e abstratos. No mesmo caminho, a extensão, minorizada, vivencia uma prática dissociada, revelando-se espontaneísta e pragmática. Contradições que sustentam uma prática educativa alienada das condições sociais que a determinam.

Neste conflitante cenário, imbrica-se uma inquietação, a necessidade de se discutir e, principalmente, de se prover um modelo de ensino pautado nas simbióticas relações entre educação e trabalho, ou seja, um processo construído na e para realidade.

Debruçando-se sobre esta perspectiva, dever-se-ia esperar dos cenários extensio- 
nistas, desde que indissociáveis, a reflexão de uma interdependência entre o pensar e o fazer. Uma premissa que pode ser amparada no reconhecimento da prática como fundamento, critério e finalidade da teoria, na medida em que todo conhecimento teórico emerge e se transforma em sua real prática social.

Por fim, atravessado pela provocação, o presente estudo não apenas se justifica, como alicerçou o seu propósito, o de prover um recorte analítico das experimentações político-pedagógicas vivenciadas pelo Projeto de Extensão Sala de Espera do Campus Avançado de Governador Valadares da Universidade Federal de Juiz de Fora, PESE-UFJF/GV.

\section{Percurso metodológico}

Em linhas gerais, este trabalho, transversal, foi qualitativamente estruturado sob estratégia narrativo-descritiva e moldado à técnica argumentativa.

Trata-se do desdobramento final da pesquisa "Sala de espera em extensão: relato das experiências vivenciadas", aprovada, sob parecer de número 2.056.630/10-05-2017, pelo Comitê de Ética em Pesquisa da Universidade Federal de Juiz de Fora, segundo Resolução 510/20166 do Conselho Nacional de Saúde.

Como já exposto, o objeto do estudo se delineou na compreensão dos dispositivos político-pedagógicos atrelados à dinamização do Projeto de Extensão Sala de Espera do Campus Avançado de Governador Valadares da Universidade Federal de Juiz de Fora.

Nessa toada, creditou-se o real papel desta produção científica, o de ser um espaço guiado pelos aprendizados e evidências do fundamental papel da extensão universitária na qualidade da formação acadêmica.

Por sua transversalidade, entre novembro de 2015 a dezembro de 2016, as apreciações envolvem as vivências extensionistas desenvolvidas na Unidade de Atenção Primária de Saúde, UAPS, do bairro Esperança, no município de Governador Valadares (GV-MG). Neste espaço de referência estão adstritas a população de três Estratégias de Saúde da Família, ESF (ESF-Esperança, ESF-Nossa Senhora das Graças e ESF-Distrito Sanitário III).

Indo além, no tocante aos investigadores, docentes e discentes da equipe extensionista do PESE-UFJF/GV, merece destacar a fusão de seus papéis, ora observadores, ora observados.

É nesta duplicidade de funções que se consagra a observação participativa, pois nela, segundo Creswell7, p.188, "os investigadores identificam explicitamente seus vieses, valores e interesses pessoais". Corroborando, Bell8, p.161, reconhece que

a observação participativa não é um método fácil de realizar, ou de analisar, mas apesar dos argumentos de seus críticos, é um estudo sistemático e disciplinado que, se bem realizado, ajuda muito no entendimento das ações humanas e traz consigo novas maneiras de encarar o mundo social. ${ }^{8}$

Deste percurso foi direcionada a coleta de dados. Essencialmente narrativo-descritiva, foi instrumentalizada pela utilização do Relatório de atividades do PESE-UFJF/GV, que além de informações textuais, trazem vídeos, áudios transcritos e arquivos fotográficos.

Contíguo, após assinatura do Termo de Consentimento Livre e Esclarecido (TCLE), seguiu o processo analítico dos fatos. Neste momento, adentraram-se os elementos argumentativos do estudo, embebidos tanto pelas interpretações de seus sujeitos-autores, quanto pelo confronto junto à literatura científica. O que se reforçou ainda mais o papel ativo dos pesquisadores, aqui, descobridores do significado das ações e das relações por eles vividas e percebidas. 
De acordo com Minayo9, p. 24,

Os autores que seguem tal corrente não se preocupam em quantificar, mas, sim, em compreender e explicar a dinâmica das relações sociais que, por sua vez, são depositárias de crenças, valores, atitudes e hábitos. Trabalham com a vivência, com a cotidianeidade e também com a compreensão das estruturas e instituições como resultados da ação humana objetivada. Ou seja, desse ponto de vista, a linguagem, as práticas e as coisas são inseparáveis.9

Enfim, calcada no empoderamento de seus elementos empíricos, esta investigação não se baseou em testar hipótese, pelo contrário, galgou-se aqui uma oportunidade de ofertar a outros leitores um momento de autoanálise, afinal, muitos podem se identificar com determinados aspectos, situações e reflexões.

\section{Resultados em discussão}

Buscando otimizar o desenvolvimento de suas ações, o Projeto de Extensão Sala de Espera do Campus Avançado de Governador Valadares da Universidade Federal de Juiz de Fora, PESE-UFJF/GV foi didaticamente sistematizado em dois períodos, Pré-intervenção e Intervenção.

Do primeiro, sequencialmente, se consubstanciaram três atividades: a Contextualização dos acadêmicos extensionistas, a Pactualização do enlace ensino-serviço-comunidade e a Estruturação e ambientalização das equipes de trabalho.

Como ponto de partida, mais precisamente nos meses de novembro e dezembro de 2015, coube aos coordenadores/docentes do PESE-UFJF/GV promoverem a imersão dos discentes selecionados frente aos seus futuros desafios práticos - aqui, materializados no desenvolvimento de atividades de educação em saúde na sala de espera da UAPS do bairro Esperança, GV-MG.

Deste ciclo teorizante se desprenderam quatro encontros, que juntos totalizaram oito horas (Dias 01 e 02 - 20/11 e 27/11/2015 - 04 horas - Promoção e prevenção em saúde nos ambientes de espera: potencialidades e desafios; Dias 03 e 04 - 04/12 e 11/12/2015 - 04 horas - Planejamento estratégico situacional: a dinamização de atividades educativo-preventivas em salas de espera).

Daqui merecem destaque as técnicas de mediação, que se deram por diferentes estratégias problematizadoras de ensino, destacando aulas expositivas, leitura crítica de artigos científicos, grupos de discussão e oficina para construção de materiais didáticos para educação em saúde.

Refletindo sobre o retratado, pode-se deduzir uma ampliação no olhar dos discentes junto às complexidades histórico-existenciais nos polissêmicos ambientes de espera, reconhecendo neles um intrincado cenário de práticas e representações em saúde.

Inferência que se faz presente em diversos estudos10-13 e que se clareia ainda mais no dito por Teixeira e Veloso14, p.322,

Nesse território ocorrem interações, nem sempre harmônicas, entre o saber oficial em saúde e o popular, nas quais as pessoas expressam suas subjetivações, formas de ser e maneira de se cuidarem. Quando entramos nesse cenário, com propósito educativo, identificamos as transversalidades entre as expressões psicossociais das pessoas e linguagem técnica e científica.14

Acadêmicos contextualizados, partiu-se para a Pactualização do enlace ensino-serviço-comunidade. 
Na verdade, o referido acordo se iniciou em 2014, onde, macropoliticamente, a Prefeitura Municipal de Governador Valadares (PMGV), representada pelo Departamento de Saúde Bucal (DSB/GV), alocado na Secretaria Municipal de Saúde do município (SMS/ GV), não apenas revelou algumas de suas demandas reprimidas, bem como balizou a academia no como e onde ela poderia colaborar.

Dentre tantas necessidades, distinguiu-se o desenvolvimento de atividades educativo-preventivas em salas de espera das Unidades de Atenção Primária de Saúde. Uma insuficiência que justificou e alimentou, ainda em 2014, a criação e a implantação do PESE-UFJF/GV.

No intuito de pluralizar sua cobertura, desde sua concepção, o projeto vem se desenrolando de forma itinerante. Neste arranjo, anualmente (dois semestres letivos), os cenários extensionistas se diversificaram. Afinal, vínculo em extensão não se materializa na dependência, pelo contrário, atrela-se ao grau de autonomia alcançado junto a seus assistidos.

Assim, no fim de 2015, sob consentimento do DSB/GV, o PESE-UFJF/GV se introduziu na UAPS do bairro Esperança.

A partir de então, mais precisamente no dia 08/01/2016, aconteceu na unidade atendida uma reunião para o alinhamento micropolítico do processo de trabalho.

Deste encontro, conforme os enfermeiros gestores da UAPS, pautados no quantitativo e na heterogeneidade dos usuários, foram definidos os dias (terças, quartas e sextas-feiras) e os horários para o desenvolvimento das atividades extensionistas (de 7:00 às 8:00 horas). Além disso, determinou-se que os conteúdos temáticos a serem trabalhados pelo PESE-UFJF/GV seriam designados pela agenda da unidade de saúde.

Do pacto, em síntese, notabilizaram-se os benefícios trazidos pela articulação da tríade Ensino (cenários formativos contextualizados e afinados aos princípios e diretrizes do SUS), Serviço (sala de espera dinamizada conforme as demandas próprias da UAPS/ Esperança) e Comunidade (acesso a serviços de promoção e prevenção em saúde durante o momento de espera).

Ademais, cabe destacar que a lógica de atenção prevista pelo PESE-UFJF/GV vai ao encontro dos preceitos de Freire15. Segundo o educador15, os ideais dos projetos extensionistas devem romper com o ainda frequente movimento de "via de mão única", onde tudo é focado aos ensejos paternalistas da universidade, que vai à sociedade levar algo de sua especialidade, logo, se tornando antidialógica e manipuladora.

Neste processo, consumado pela quebra da verticalidade, a extensão se define aos moldes da "via de mão dupla". Assim, conforme Freire15, sustentada na integralidade da vida humana, a academia não apenas leva informações para a comunidade (ensino), como traz para o cenário universitário vivências (extensão) e dados coletados e interpretados cientificamente (pesquisa).

Em outras palavras, cabem as reflexões de Almeida, Pereira e Oliveira3, que reconhecem na extensão o território para se concretizar as tão almejadas indissociabilidade (ensino-pesquisa-extensão) e integração (ensino-serviço-comunidade).

Seguindo, o período Pré-intervenção se encerrou com a Estruturação e ambientalização das equipes de trabalho.

O grupo extensionista foi construído multiprofissionalmente, abrangendo cinco cursos de saúde da UFJF/GV (Farmácia, Fisioterapia, Medicina, Nutrição e Odontologia).

Para cada segmentação formativa, foram alocados um Coordenador/docente e dois discentes bolsistas, portanto, totalizando quinze integrantes. 
Confrontando a equipe do PESE-UFJF/GV com as necessidades da sala de espera da UAPS/Esperança, montaram-se três pontas de trabalho (Grupo I/G1, terça-feira; Grupo II/G2, quarta-feira; Grupo III/G3, sexta-feira). Cada extremidade composta por cinco membros, destes, pelo menos um professor e três discentes de cursos distintos.

Todavia, chegar neste quadro foi encontrar a zona de equilíbrio entre os pesos de duas pontas. De uma, o ordenamento qualitativo das equipes, vitalmente composta por graduandos de diferentes especialidades e tutelada por pelo menos um docente. Da outra, o ajuste dos conflituosos horários acadêmicos.

Enfim, na ideia de se ambientalizar ao cenário extensionista, cada grupo teve sua visita agendada na UAPS, G1 (12/01/2016), G2 (13/01/2016) e G3 (15/01/2016). Iniciado às 7:00 horas, este momento observacional foi dirigido pelos enfermeiros gestores da unidade. Aqui, além do reconhecimento do espaço físico, foram apresentados os recursos humanos, os serviços ofertados, a cobertura populacional, bem como a caracterização de seus usuários em horário de espera.

Do vivenciado, pode-se admitir que a sistemática de trabalho abraçada pelo PESE-UFJF/GV consoa ao mencionado nos estudos de Peduzzi16,17. O autor reconhece na equipe multiprofissional uma articulação contínua de processos de trabalho distintos, ou seja, conexões e interfaces entre as intervenções técnicas peculiares de cada área profissional16,17. Na prática, nos cenários de atenção em saúde, trabalhar em equipe de modo integrado significa valorizar o outro na produção de cuidados, o que reflete diretamente em uma prestação de serviços mais contextualizada e humanizada16,17.

Encerrada a Pré-intervenção, abriu-se a Intervenção. Na transição destes períodos, a equipe coordenadora/docente do projeto se via diante de um grande desafio: o de prover um modelo extensionista que extrapolasse o fazer, que também alcançasse o pensar e o refletir. Afinal, extensão se estreita com a relação ensinar/aprender a fazer.

Defronte à situação, o PESE-UFJF/GV se viu afinado às idealizações dos trabalhos de Almeida, Pereira e Oliveira3 e Almeida, Pereira e Bara4, que materializaram o instrumento "TPC" (Imagem 1). Segundo os autores, p. 746,

O instrumento apresentado [...] se desenvolve em três etapas: Teorizando ("o pensar"), Praticando ("o fazer") e Criticando ("o refletir"), sendo por isso denominado TPC. Sistematicamente, as etapas se complementam, trazendo em seu bojo conceitual a relação entre planejamento estratégico com a eficácia, eficiência e efetividade de ações de educação em saúde.3

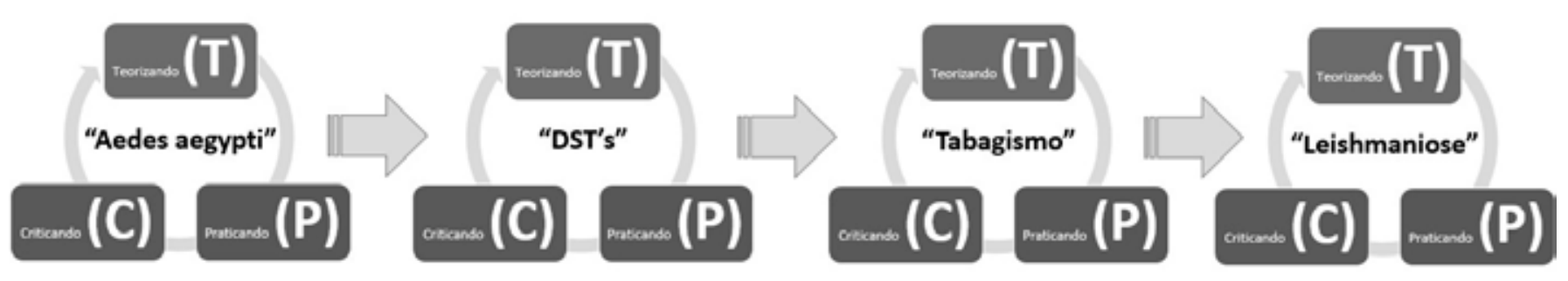

Imagem 1: Instrumento "TPC" (Almeida, Pereira, Oliveira, p.746, 2016)3 
Aqui cabem as considerações de Almeida, Pereira e Bara4, p. 129: o "TPC", não se consagra como uma fórmula mágica para se fazer extensão, pelo contrário, a ferramenta apenas retrata a rica lógica do ensinar a fazer contextualizado. Além, conforme os mesmos autores, o verdadeiro intuito do instrumento se efetiva na redução do persistente hiato entre teoria e prática, que, consecutivamente, se choca no necessário e desafiante alinhamento dos tempos de trabalho entre serviço e academia4.

Não obstante, norteadas pela sistematização do "TPC", em 2016, todas as vivências experimentadas pelo PESE-UFJF/GV se sequenciaram em três etapas: Teorizando/O pensar; Praticando/O fazer; Criticando/O refletir.

Dentro dos preceitos do instrumento, o ponto de partida para se planejar estrategicamente atividades extensionistas se dá com a Identificação do(s) problema(s).

Assim, na conjuntura ideológica do projeto, este momento se sustentou em um primordial questionamento: o que será abordado na sala de espera?

Permeados pela indagação, a equipe do projeto buscou sua resposta no resgate de sua prévia pactualização, onde ficara definido o papel ativo dos gestores da unidade de saúde na determinação dos enfoques a serem abarcados.

Desta lógica, para o ano de 2016, desdobraram-se, paulatinamente, os quatro desafios temáticos enfrentados pelo PESE-UFJF/GV na UAPS/Esperança-GV (1.Aedes aegypti; 2.Doenças sexualmente transmissíveis; 3.Tabagismo; 4.Leishmaniose - Imagem 2).

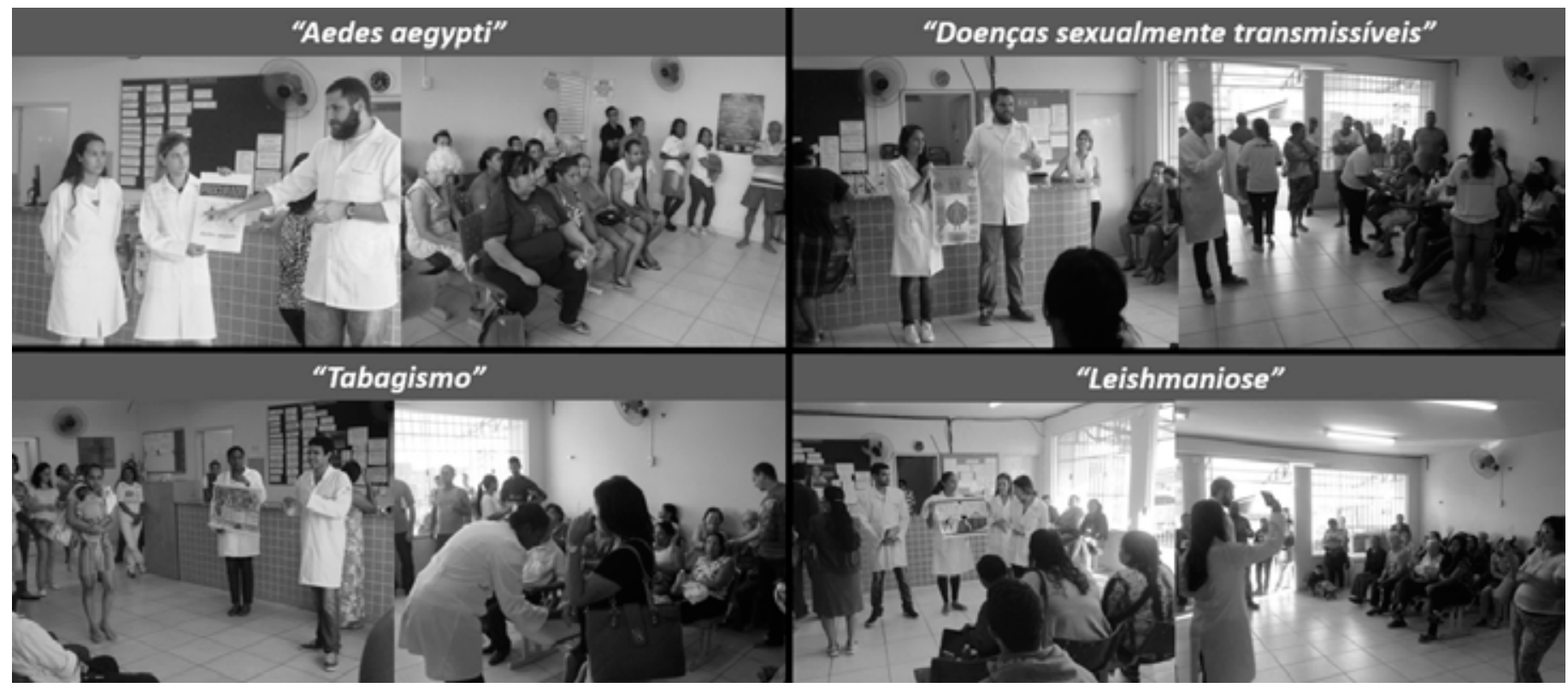

Imagem 2: "TPC" nas vivências temáticas do PESE-UFJF/GV (Autores, 2018)

Contudo, apesar de sua importância, Almeida, Pereira e Oliveira3 reiteram que este período de escuta é burlado com frequência por projetos de extensão, consequentemente, p. 747, "gerando um modelo de trabalho vertical-paternalista, assistencialista e, principalmente, descontextualizado do controle social".

Retomando a continuidade do "TPC", consciente de seus enfrentamentos, a equipe extensionista segue para a Interiorização acadêmica. Exercício que se replicou nas quatro vivências experimentadas pelo PESE-UFJF/GV. 
No âmbito, os docentes do projeto, coordenadores, solicitaram aos acadêmicos extensionistas um levante bibliográfico, através de conteúdos já desenvolvidos em salas de aula (bagagem cognitiva) e/ou disponíveis em bases científicas indexadas.

Indo além, otimizando a coleta de dados, dentro das concepções ativo-problematizadoras da educação em saúde, forneceu-se aos graduandos um questionário, sendo ele composto por três perguntas direcionadoras (O que é?; Como percebo no meu corpo/ espaço; Como prevenir/tratar?).

Após períodos de estudo, em média de duas semanas, a equipe PESE-UFJF/GV se reunia para analisar e até mesmo alinhar, sob a pluralidade de seus olhares profissionais, os conhecimentos adquiridos.

Esmerando um pouco mais, estes encontros se findaram com uma desafiante provocação: Como levar as informações discutidas para o cenário prático?

No fim de contas, o papel da formação universitária não se restringe ao fornecimento de conhecimentos para o aluno (aprendizado). Na verdade, este processo se encerra quando os graduandos se reconhecem como agentes transformadores de uma realidade social (apreensão e carreamento).

Adensando um pouco mais, neste momento, o papel ativo-indutor do "TPC" na tão almejada indissociabilidade formativa se realçou. Afinal, daqui se viu o acadêmico, em extensão, resgatando (ensino) e construindo (pesquisa) saberes.

Uma reflexão que se encorpa com o firmado por Freire15, p. 27, "A prática, por sua vez, ganha uma significação nova ao ser iluminada por uma teoria da qual o sujeito que atua se apropria lucidamente".

Dando continuidade, ainda atravessado pelo contexto provocativo, o PESE-UFJF/GV se despertou para a construção do Plano de ação.

Com durabilidade média de quatro encontros, dentro das prerrogativas preconizadas pela metodologia "Brainstorming"18,19, a dinamização deste período seguiu as orientações do questionário proposto na metodologia "TPC"3,4, também estruturado por oito questões direcionadoras: O quê? Quem? Onde? Quando? Como?, Quanto custa? Por quê? e Como avaliar?.

Em acordo com Almeida, Pereira e Oliveira3, p. p.747,

Esse instrumento traz em sua operacionalidade a construção de um plano de ação mais consoante com as representatividades dos campos de atuação da extensão universitária, ou seja, aproxima-se o máximo possível das integralidades imbuídas nos problemas identificados. 3

Desta forma, desdobraram-se os planejamentos estratégicos das vivências temáticas (1.Aedes aegypti; 2.Doenças sexualmente transmissíveis; 3.Tabagismo; 4.Leishmaniose) desenvolvidas na UAPS/Esperança.

Salienta-se que a construção de todas as atividades de educação em saúde se deu pelo mesmo desenho esquemático, do qual se sequenciaram dois movimentos, um informativo e outro de continuidade.

Do primeiro, convergiu-se a elaboração de uma palestra motivacional, um importante procedimento coletivo com função dialógica.

Neste momento, objetivando o empoderamento dos usuários em espera, se distinguiu a organização das informações a serem repassadas. Esta ordenação, nomeada como "Triangulação problematizadora para a Educação em Saúde" (Imagem 03), foi apoiada nas mesmas questões que nortearam a prévia coleta de dados feita pelo acadêmicos 
extensionistas ("O que é?"; "Como percebo no meu corpo/espaço; "Como prevenir/tratar?"). No tempo, frisou-se também a preocupação com o controle da durabilidade da atividade, entre dez e quinze minutos.

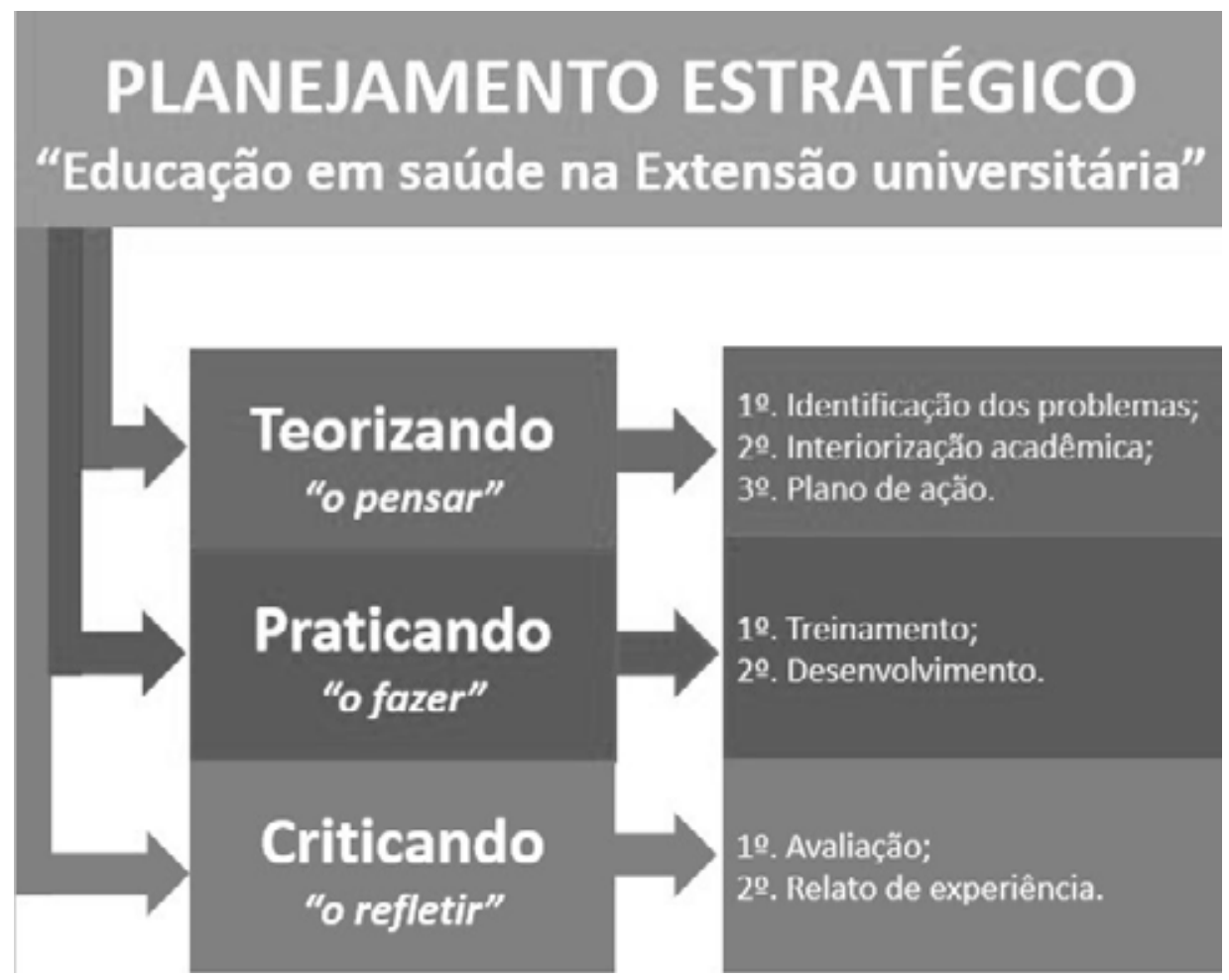

Imagem 3: "Triangulação problematizadora para a Educação em Saúde" (Autores, 2018)

Já o segundo movimento, concentrou-se na ampliação e no carreamento das informações a serem trabalhadas na UAPS/Esperança.

Daqui definiu-se a necessidade de se produzir materiais didáticos de apoio, que, sob acordo prévio com a coordenação da unidade, ficariam afixados em local estratégico ("Cantinho da UFJF/GV"). Assim, além de serem instrumentos para dinamizar a sala de espera pela equipe do PESE-UFJF/GV, estes apetrechos poderiam ser utilizados tanto por usuários em outros momentos de espera, quanto pela própria equipe de saúde em outras estratégias de atenção, como visita domiciliar e grupos operativos.

Analisando a lógica educativa proposta e utilizada pelo projeto, pode-se afirmar que ela não se reduz a um conjunto de técnicas e procedimentos. Devido ao enlace ensino-serviço-comunidade, a concepção de todas as atividades partiu do contexto social ao qual seriam inseridas. Assim, mais importante que os próprios procedimentos didáticos, é ter, respectivamente, consciência e conhecimento do "que" e "quem" serão ensinados.

Além do mais, esta pedagogia histórico-crítica encontra suporte nas reflexões de Freire15, que reconhece na prática social os pontos de partida e chegada da educação.

Encerrado seu estágio observacional (Teorizando/O pensar), os extensionistas partiram para a etapa Praticando/O fazer.

O ciclo prático se iniciou com o Treinamento, onde, em todas as vivências, os discentes apresentaram e desenvolveram junto à coordenação docente do PESE-UFJF/GV, sob 
papel de usuários em espera, as atividades programadas. No ensejo, foram feitos, pela equipe de trabalho, os ajustes e os alinhamentos finais necessários.

Pode-se afirmar que esta etapa teve papel fundamental na preparação da equipe extensionista. Afinal, ela marca, de forma gradual, a mudança nas funções dos discentes, que se deslocam da condição de observadores para interventores.

Almeida e Oliveira Júnior20, p. 64, ainda complementam, treinar não é eximir-se do erro, pelo contrário, no treino, através da mimetização de uma realidade, vislumbra-se capacitar uma equipe em prover estratégias secundárias para se contornar os tão frequentes e esperados obstáculos da vida real20.

Assim, previamente treinados, chega o tão esperado Desenvolvimento dos planos de ação.

Com cobertura média de trinta e cinco usuários, nos dias (terças, quartas e sextas-feiras) e horários previstos (das 7:00 às 8:00 horas), a equipe PESE-UFJF/GV celebrou, em seus respectivos tempos, suas experimentações (1.Aedes aegypti; 2.Doenças sexualmente transmissíveis; 3.Tabagismo; 4.Leishmaniose), todas vivenciadas na sala de espera da UAPS/Esperança (Imagem 04). "Como prevenir/tratar?" 3

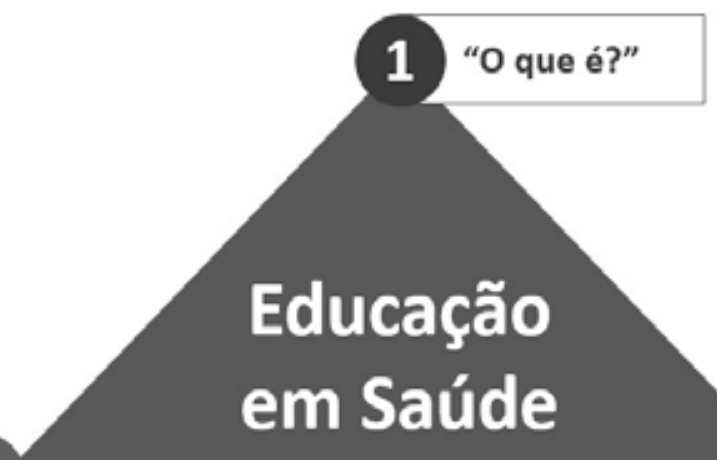

"Como percebo no meu corpo/espaço?"

Imagem 4: Educação em Saúde na Sala de espera da UAPS/Esperança, GV-MG (Autores, 2018)

Contudo, apesar do êxito nas execuções dos planos de ação, ficou evidente o sobrepujamento da realidade prática sobre as expectativas teóricas.

Foi justamente deste confronto entre teoria/expectativa e prática/realidade que o PESE-UFJF/GV se percebeu como agente ativo no processo de aprendizagem dos extensionistas. Afinal, os acadêmicos puderam perceber que suas funções extrapolavam o executar. Deles foram também exigidas outras habilidades, pautadas na plasticidade do adaptar, do criar, do suprimir, do postergar, e, principalmente, do reinventar.

Assim os discentes tiveram a oportunidade de conhecer o maior desafio de um profissional da saúde, o saber lidar com os desafios e, até mesmo, entraves da realidade. Deixando de ver estas situações como alimento para frustrações, pelo contrário, passando a encará-las como uma oportunidade de melhoramento continuado.

Percepções que se alicerçam no firmado por Almeida, Pereira e Oliveira3, p.747, "uma equipe aprende com os acertos e se transforma com os erros". 
Indo além, certifica-se que a teoria não se torna diminuta diante da realidade, pelo contrário, ela ganha forma, sentido, em suma, se justifica.

Neste prisma, como dito por Rossetti21, p.77, não se deve adaptar os pacientes à ciência, deve-se adaptar a ciência às pessoas. Complementando, o mesmo autor, p.27, aos doutores, ensiná-los a pensar, não aplicar técnicas ou receitas.

É óbvio que não se poderia esperar, pelo menos em totalidade, a compreensão dos graduandos extensionistas das reflexões supradescritas. Por isso a terceira e última etapa do "TPC", Criticando/O refletir, se fundamentou.

Como previsto, o percurso de reflexão proposto pelo instrumento se iniciou com a Avaliação e se encerrou com a construção do Relato de Experiência.

Desta forma, intermediado pelos professores coordenadores do PESE-UFJF/GV, o momento avaliativo se instalou com o levante dos pontos positivos/forças e negativos/fragilidades, percebidos pelos discentes durante as ações extensionistas desenvolvidas na sala de espera da UAPS/Esperança.

Para otimizar este período interpelativo, lançou-se o questionamento: Confrontando o planejado com o executado, quais os pontos positivos/forças e negativos/fragilidades que merecem destaque em nosso processo de aprendizagem?

Na somatória de todas as vivências experimentadas, dos elos de força apontados pelos discentes se destacaram: 1. Interpessoalidade e valorização do conhecimento da população; 2. Escolha dos temas; Atividades dinâmicas; 3. Formação profissional; 4. Planejar e fazer atividades dinâmicas; 5. Trabalhar em equipe multiprofissional; 6. Escutar o serviço; Ambientalização; 7. Quantidade e receptividade dos usuários; 8. Participação, mesmo como ouvintes, da equipe profissional da UAPS; 9. Presença do corpo docente como observadores; 10. Vínculo da UFJF-GV com o serviço; 11. Entender o ambiente de espera.

Através dos argumentos dos discentes, muitos destes pontos se clarificaram, eu pude perceber que muitos deles tinham até mais conhecimento do que nós (JNSM/Fisioterapia); eu mesma aprendi muitas coisas durante ação (JNSM/Fisioterapia); fez toda a diferença visitar a unidade antes (QSCB/Nutrição.); a unidade atende muita gente, a demanda é grande (APB/Nutrição); tinham muitas pessoas, ficamos até preocupados com as que ficaram do lado de fora (DMO/ Odontologia); foi muito legal ver o pessoal da unidade participando da ação, fomos muito bem acolhidos (FHLS/Farmácia); o pessoal da unidade participou ativamente, falando da distribuição gratuita de preservativos e dos serviços de referência (VHM/Medicina); a parte da dinâmica foi fundamental, penso que sem ela não teríamos nenhuma participação ativa dos usuários (QSCB/Nutrição); o professor percebeu meu nervosismo e me ajudou na hora certa, depois consegui me concentrar e retomar minha fala (LMA/Odontologia); o Cantinho da UFJF nos identificou, a comunidade passou a nos conhecer (DMO/Odontologia); desta vez, a movimentação na unidade não me desconcentrou, entendi que sala de espera é assim mesmo, lá estão muitas demandas (VHM/Medicina).

Quanto às fragilidades, os extensionistas evidenciaram: 1. Dificuldade em lidar com os ruídos no ambiente de espera; 2 . Ampliar o tempo de treinamento; 3. Nervosismo e falta de experiência; 4. Deficiência nos instrumentos avaliativos; 5. Falta de Identificação da equipe; 6 . A temática doenças sexualmente transmissíveis; 7. Falta de divulgação virtual.

Assertivas que se delinearam em algumas ponderações feitas pelos extensionistas, 
lidar com a agitação, conseguir a atenção dos pacientes nestas condições é a parte mais difícil (JAN/ Farmácia); eu fiquei um pouco nervoso com a apresentação, achei que era mais simples, precisamos treinar mais antes de ir para lá (VHM/Medicina); acho que nosso nervosismo foi devido a falta de experiência do grupo em lidar com ambientes agitados (FHLS/Farmácia); as percepções da atividade ficaram apenas nas minhas impressões, acredito que seria fundamental criarmos um questionário para analisarmos a opinião dos pacientes ( $M M$ / Medicina); acho que seria interessante estarmos uniformizados, precisamos mostrar que somos da universidade, que estamos devolvendo algo para a comunidade (DMO/Odontologia); de todas as experiências que tivemos, esta foi a mais difícil, falar de sexo ainda é tabu, as pessoas ficam intimidadas, principalmente as mulheres, que ali eram a maioria (JNSM/ Fisioterapia); devíamos criar uma página virtual em uma rede social, hoje o acesso a internet é muito grande, principalmente para os indivíduos mais jovens (MM/Medicina).

Continuando, alimentados pelas suas próprias reflexões, consensualmente, o grupo extensionista não apenas reconheceu êxito nas suas atividades programadas, bem como incitaram o potencial dos ambientes de espera na efetividade de atividades educativo-preventivas.

Reflexões que encontraram suporte em diversos estudos10-14, que consagram a sala de espera como um território dinâmico e fértil para a implantação de ações educativas. Nesta lógica, estes espaços podem contribuir significativamente para a promoção da saúde, prevenção de agravos e encaminhamento para outras atividades, portanto, encorpando e otimizando ainda mais o papel da atenção primária junto aos serviços de saúde prestados pelo Sistema Único de Saúde, SUS10-14.

Marcando o ponto final do "TPC", se evidencia a construção do Relato de experiência. De acordo com Almeida, Pereira e Oliveira3, p. 747, entre as diversas metodologias, destaca-se o "relato de experiência", ressaltando que sua construção não deve ser direcionada apenas aos acertos, ou seja, deve-se oferecer espaço também para discutir erros e fragilidades.

Assim orientados, a equipe extensionista do PESE-UFJF/GV encerrou suas atividades através do desenvolvimento de suas contribuições científicas.

Deste processo, até então, das quatro vivências temáticas experimentadas (1.Aedes aegypti22; 2.Doenças sexualmente transmissíveis23; 3.Tabagismo24; 4.Leishmaniose), algumas publicações já aconteceram, além da aprovação e do andamento avaliativo de outros trabalhos.

Por fim, na intenção de justificar este momento, Almeida, Pereira e Oliveira3, p.747, argumentam que

reconhecendo o universo da extensão como inesgotável para a aplicação dos conceitos disseminados em sala de aula e para o alicerce da pesquisa, é fundamental que as experimentações extensionistas sejam compartilhadas, reconhecendo-se na publicação científica um dos mais importantes instrumentos de divulgação.3

\section{Conclusão}

Após análise detalhada dos dispositivos político-pedagógicos atrelados à dinamização do Projeto de Extensão Sala de Espera do Campus Avançado de Governador Valada- 
res da Universidade Federal de Juiz de Fora, algumas inferências se destacaram:

a importância da capacitação e da ambientalização dos discentes extensionistas antes de inseri-los em campo, o que resultou na ampliação de seus olhares frente às complexidades histórico-existenciais dos ambientes de espera;

o enlaçamento ensino-serviço-comunidade, que se deu através dos alinhamentos macro e micropolíticos, que, somados, trouxeram simbióticas relações, pautadas no rompimento de protagonismos;

o multiprofissionalismo, que ofertou aos graduandos a oportunidade de aprender a prover ações educativo-preventivas sob a pluralidade de diversos olhares profissionais;

a estruturação das equipes extensionistas em frentes de trabalho, o que ampliou a cobertura populacional assistida na sala de espera da UAPS/Esperança;

a escuta do serviço na identificação dos problemas, o que garantiu o desenvolvimento de ações, sob "via de mão dupla", contextualizadas e voltadas às demandas dos usuários;

a efetividade do instrumento "TPC", que, através da tríade "teorizar-praticar-criticar", proporcionou os discentes experimentarem, através da extensão, uma lógica de trabalho indissociável (ensino-pesquisa-extensão);

o reconhecimento do potencial dos ambientes de espera como território dinâmico e fértil para a implantação de ações educativas, o que se pautou no êxito das vivências experimentadas ("Aedes aegypti", "Doenças sexualmente transmissíveis", "Tabagismo" e "Leishmaniose") pela equipe do PESE-UFJF/GV;

a disseminação, em espaços científicos, dos aprendizados advindos da extensão, o que incentivou a construção e publicação de relatos de experiência.

Por fim, guiado pelas reflexões acima elencadas, acredita-se que este trabalho reforça ainda mais o fundamental papel da extensão universitária junto a uma formação acadêmica de qualidade. Depositou-se nas vivências experimentadas uma oportunidade de preparação dos futuros profissionais de saúde a uma prática direcionada às solutividades das verdadeiras aflições que assolam a população brasileira. Afinal, extensão é isso, inserir vida no ensino superior, é dinamizar espaços em prol da tão almejada coletividade.

\section{Referências}

1. ALBUQUERQUE, Verônica Santos; GOMES, Andréia Patrícia; REZENDE, Carlos Henrique Alves de; SAMPAIO, Marcelo Xavier; DIAS, Orlene Veloso; LUGARINHO, Regina Maria. A integração ensino-serviço no contexto dos processos de mudança na formação superior dos profissionais da saúde. Rev. Bras. Educ. Med. 2008, vol.32, n.3, pp.356-362.

2. MADEIRA, Miguel Carlos. Ensino, Pesquisa, Extensão. In: Carvalho, Antônio César Perri; Kriger, Léo (organizadores). Educação Odontológica. São Paulo: Editora Artes Médicas, 2006. pp.97-103.

3. ALMEIDA, Luiz Eduardo; PEREIRA, Marília Nalon; OLIVEIRA, Valéria. Governador Valadares (MG) em Extensão: Interfaces para a Dinamização e Instrumentalização do Cenário Extensionista em um Campus Recém-Implantado. Rev. Bras. Educ. Med. 2016, vol.40, n.4, pp.743-750.

4. ALMEIDA, Luiz Eduardo; Pereira, Marília Nalon; BARA, Éllen Freitas. Projeto de Extensão Sabiá: a introdução de uma prática integralizadora no ensino odontológico. In: Almeida, Luiz Eduardo de (organizador). Pró-Saúde: Ensino, Pesquisa e Extensão. Juiz de Fora: Editar Editora Associada Ltda, 2009. pp.126-164. 
5. TINTI, Élidi Cristina. Dilemas entre teoria e prática a partir da formação profissional e das condições objetivas do trabalho cotidiano. In: UNESP \\. Capitalismo, trabalho e formação profissional: dilemas do trabalho cotidiano dos assistentes sociais em Ribeirão Preto. São Paulo: Editora UNESP, 2015. pp.97-131.

6. BRASIL. Ministério da Saúde. Conselho Nacional de Saúde. Resolução n-510, de 07 de abril de 2016. Brasília: Ministério da Saúde, 2016.

7. CRESWELL, John W. Projeto de Pesquisa: Métodos qualitativo, quantitativo e misto. Porto Alegre: Editora Artmed, 2007. 248p.

8. BELL, Judith. Projeto de Pesquisa: Guia para pesquisadores iniciantes em educação, saúde e ciências sociais. Porto Alegre: Editora Artmed, 2008. 224p.

9. MINAYO, Maria Cecília de Souza. Ciência, técnica e arte: o desafio da pesquisa social. In: MINAYO, Maria Cecília de Souza; Deslandes, Suely Ferreira (organizadoras). Pesquisa Social: teoria, método e criatividade. Rio de Janeiro: Editora Vozes, 1994. pp.09-29.

10. MIALHE, Fábio Luiz; JÚNIOR, Miguel Morano; SILVA, Renato Pereira da. Sala de espera como ambiente para práticas em educação em saúde. Revista UNINGÁ. 2008, vol.17, n.-, pp.101-106.

11. RODRIGUES, Andréia Dornelles; DALLANORA, Carlise Rigon; ROSA, Jonathan da; GERMANI, Alessandra Regina Müller. Sala de espera: um ambiente para efetivar a educação em saúde. Vivências. 2009, vol.5, n.7, pp.101-106.

12. VALENTE, Maria Anete Santana; ANDRADE, Adriana Guedes de; ALC NTARA, Poliana Gomes de; SILVA, Pamela Souza Almeida. O que te espera na Sala de Espera: educação em saúde em Unidades de Atenção Primária à Saúde (UAPS) de Governador Valadares (MG). Caminho Aberto - Revista de Extensão do IFSC. 2015, vol.1, n.2, pp.137-141.

13. ALMEIDA, Luiz Eduardo; ANDRADE, Larissa Martins Duarte; ZACARON, Katy Andrade Monteiro. Sala de espera em extensão: percursos para a implantação e consolidação de um projeto multiprofissional. Caminho Aberto - Revista de Extensão do IFSC. 2016, vol.3, n.4, pp.124-127.

14. TEIXEIRA, Enéas Rangel; VELOSO, Raquel Coutinho. O grupo em sala de espera: território de práticas e representações em saúde. Texto Contexto Enferm. 2006, vol.15, n.2, pp.320-325.

15. FREIRE, Paulo. Extensão ou comunicação?. Rio de Janeiro: Editora Paz e Terra, 1983. 93p.

16. PEDUZZI, MARINA. Equipe multiprofissional de saúde: conceito e tipologia. Rev. Saúde Pública. 2001, vol.35, n.1, pp.103-109.

17. PEDUZZI, Marina; NORMAN, lan James; GERMANI, Ana Claudia Camargo Gonçalves; SILVA, Jaqueline Alcântara Marcelino da; SOUZA, Geisa Colebrusco de Souza. Educação interprofissional: formação de profissionais de saúde para o trabalho em equipe com foco nos usuários. Rev Esc Enferm USP. 2013, vol.47, n.4, pp.977-983.

18. BRAIA, Filipa; CURRAL, Luís; GOMES, Catarina. Criatividade em contexto organizacional: o impacto de recompensas extrínsecas e do feedback negativo no desempenho criativo. Revista Psicologia. 2014, vol.28, n.2, pp.45-62.

19. NÓBREGA, Maria de Magdala; NETO, David Lopes; SANTOS, Sérgio Ribeiro dos. Uso da técnica de brainstorming para tomada de decisões na equipe de enfermagem de saúde pública. Rev. Bras. Enferm. 1997, vol.50, n.2, pp.247-256.

20. ALMEIDA, Luiz Eduardo; OLIVEIRA JÚNIOR, Gilson Irineu. Sistema de Execução do Projeto. In: Almeida, Luiz Eduardo de (organizador). Pró-Saúde: Ensino, Pesquisa e Extensão. Juiz de Fora: Editar Editora Associada Ltda, 2009. pp.: 63-86. 
21. ROSSETTI, Hugo. Saúde para a Odontologia. São Paulo: Editora Santos, 1999. 147p.

22. ALMEIDA, Luiz Eduardo; OLIVEIRA, Valéria; PEREIRA, Marília Nalon; OLIVEIRA, Diego Machado de; AGUIAR, Larisse Martins. Sala de espera em extensão: aedes aegypti em foco. Rev. APS. 2017b, vol.20, n.3, pp.456 - 460.

23. ALMEIDA, Luiz Eduardo; OLIVEIRA, Valéria; PEREIRA, Marília Nalon; OLIVEIRA, Diego Machado, AGUIAR, Larisse Martins. Sala de espera em extensão: doenças sexualmente transmissíveis em foco. Interfaces - Revista de Extensão da UFMG. 2017a, vol.5, n.1, pp.198-205.

24. ALMEIDA, Luiz Eduardo; PEREIRA, Marília Nalon; OLIVEIRA, Valéria; OLIVEIRA, Diego Machado, AGUIAR, Larisse Martins. Abordagem do tabagismo em uma sala de espera: uma experiência extensionista. Extensio: R. Eletr. de Extensão. 2018, vol.15, n.28, pp.127-136. 